\title{
PTEN regulates AMPA receptor-mediated cell viability in iPS-derived motor neurons
}

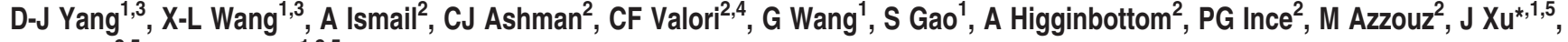 \\ PJ Shaw ${ }^{2,5}$ and K Ning ${ }^{*, 1,2,5}$
}

Excitatory transmission in the brain is commonly mediated by the $\alpha$-amino-3-hydroxy-5-methyl-4-isoxazole propionic acid (AMPA) receptors. In amyotrophic lateral sclerosis (ALS), AMPA receptors allow cytotoxic levels of calcium into neurons, contributing to motor neuron injury. We have previously shown that oculomotor neurons resistant to the disease process in ALS show reduced AMPA-mediated inward calcium currents compared with vulnerable spinal motor neurons. We have also shown that PTEN (phosphatase and tensin homolog deleted on chromosome 10) knockdown via siRNA promotes motor neuron survival in models of spinal muscular atrophy (SMA) and ALS. It has been reported that inhibition of PTEN attenuates the death of hippocampal neurons post injury by decreasing the effective translocation of the GluR2 subunit into the membrane. In addition, leptin can regulate AMPA receptor trafficking via PTEN inhibition. Thus, we speculate that manipulation of AMPA receptors by PTEN may represent a potential therapeutic strategy for neuroprotective intervention in ALS and other neurodegenerative disorders. To this end, the first step is to establish a fibroblast-iPS-motor neuron in vitro cell model to study AMPA receptor manipulation. Here we report that iPS-derived motor neurons from human fibroblasts express AMPA receptors. PTEN depletion decreases AMPA receptor expression and AMPA-mediated whole-cell currents, resulting in inhibition of AMPA-induced neuronal death in primary cultured and iPS-derived motor neurons. Taken together, our results imply that PTEN depletion may protect motor neurons by inhibition of excitatory transmission that represents a therapeutic strategy of potential benefit for the amelioration of excitotoxicity in ALS and other neurodegenerative disorders.

Cell Death and Disease (2014) 5, e1096; doi:10.1038/cddis.2014.55; published online 27 February 2014

Subject Category: Neuroscience

Amyotrophic lateral sclerosis (ALS) is a devastating neurodegenerative disorder affecting upper and lower motor neurons (MNs) and leading to death within 2-3 years from diagnosis. Between 90 and $95 \%$ of cases are sporadic in origin, whereas the remaining $5-10 \%$ of cases are familial. Of these, $\sim 20 \%$ carry mutations in the gene encoding the superoxide dismutase 1 enzyme (SOD1). ${ }^{1}$ Transgenic mice expressing mutant forms of human SOD1 are used as a model of familial ALS. ${ }^{2}$ We have defined the gene expression profiles of MNs isolated from the spinal cord of G93ASOD1 transgenic mice at different stages of disease, by combining the use of laser capture microdissection (LCM) and microarray technology. This work highlighted the involvement of metabolism in the first stages of disease, along with a substantial upregulation of transcription-related transcripts. ${ }^{3}$ Metabolic impairment suggested that astrocytes might also play a crucial role in the first stages of disease, supporting the results from other groups. ${ }^{4-6}$

Hexanucleotide GGGGCC intronic expansions in the newly identified C9ORF72 (chromosome 9 open reading frame 72) gene represents the most common cause of both familial and sporadic ALS, ${ }^{7,8}$ responsible for up to $50 \%$ of familial ALS and $\sim 10 \%$ of sporadic ALS, but to date SOD1 mutations have been the genetic subtype most widely studied and utilized to model ALS. In the presence of mutant SOD1, multiple interacting factors contribute to $\mathrm{MN}$ injury including protein misfolding and aggregation, defective axonal transport,

\footnotetext{
${ }^{1}$ East Hospital, Tongji University School of Medicine, Shanghai, China and ${ }^{2}$ Department of Neuroscience, Sheffield Institute for Translational Neuroscience (SITraN), University of Sheffield, Sheffield, UK

*Corresponding author: J Xu, East Hospital, Tongji University School of Medicine, Shanghai 200120, China. Tel: +86 (0)21 65982414; Fax: +86 (0)21 65985616; E-mail: xunymc2000@yahoo.com

or K Ning, Department of Neuroscience, Sheffield Institute for Translational Neuroscience (SITraN), University of Sheffield, 385A Glossop Road, Sheffield S10 2HQ, UK. Tel: +44 (0)114 2222245; Fax: +44 (0)114 2222290; E-mail: k.ning@sheffield.ac.uk

${ }^{3}$ These authors contributed equally to this work.

${ }^{4}$ Current address: German Centre for Neurodegenerative Diseases (DZNE), Paul-Ehrlich Strasse, 17, 72076 Tübingen, Germany

${ }^{5}$ Joint senior authors.

Keywords: PTEN; iPSCs; motor neuron; AMPA receptor

Abbreviations: PTEN, phosphatase and tensin homolog deleted on chromosome 10; AMPA, $\alpha$-amino-3-hydroxy-5-methyl-4-isoxazole propionic acid; iPSC, induced pluripotent stem cell; MN, motor neuron; ALS, amyotrophic lateral sclerosis; GluR, glutamate receptor; SOD1, superoxide dismutase 1; LCM, laser capture microdissection; C9orf72, chromosome 9 open reading frame 72; ADAR2, adenosine deaminase acting on RNA 2; SMA, spinal muscular atrophy; HDF, human dermal fibroblast; DMEM, Dulbecco's modified Eagle's medium; NEAA, nonessential amino acid; MEF, embryonic fibroblast; bFGF, fibroblast growth factor-basic; hESCs, human embryonic stem cell; ChAT, choline acetyltransferase; NGF, nerve growth factor; TUNEL, terminal deoxynucleotidyl transferase dUTP nick end labeling; CNQX, cyano-7-nitroquinoxaline-2,3-dione; PFA, paraformaldehyde; PBS, phosphate-buffered saline; RT-PCR, reverse transcription-PCR; GAPDH, glyceraldehyde-3phosphate dehydrogenase; ANOVA, analysis of variance

Received 16.10.13; revised 19.1.14; accepted 22.1.14; Edited by A Verkhratsky
} 
excitotoxicity, mitochondrial dysfunction, dysregulated transcription and RNA processing, endoplasmic reticulum stress, apoptosis, oxidative stress as well as toxicity caused by nonneuronal cells. ${ }^{9}$ Of these mechanisms, excitotoxicity is considered to play a key role. Routine excitatory transmission in the brain is predominantly mediated by $\alpha$-amino-3-hydroxy5-methyl-4-isoxazole propionic acid (AMPA) receptors. In ALS, there is a body of evidence that excitotoxicity mediated by calcium-permeable AMPA receptors contributes significantly to MN injury. Riluzole, an antiexcitotoxic agent, is the only drug proven to slow the disease progression in humans. ${ }^{10}$ AMPA receptors have been proposed to play a major role in the selective death of MNs in ALS. These characteristics are related to the way $\mathrm{MNs}$ handle $\mathrm{Ca}^{2+}$. MNs have a low $\mathrm{Ca}^{2+}$-buffering capacity and a high number of $\mathrm{Ca}^{2+}$-permeable AMPA receptors. A significantly different ratio between inhibitory and excitatory synapses was present in SOD1 ${ }^{\text {G93A }}$ mouse spinal cord slice cultures. SOD1 ${ }^{\mathrm{G} 93 \mathrm{~A}}$ MNs exhibited increased vulnerability to AMPA glutamate receptor-mediated excitotoxic stress before the onset of an overt disease phenotype. ${ }^{11}$ The levels of the glutamate receptor 2 (GluR2) AMPA subunit, which plays an important role in the maintenance of calcium impermeability of AMPA receptors, are decreased in spinal MNs before symptom onset in conjunction with a modest increase of GluR3 expression in SOD1 ${ }^{\mathrm{G} 93 \mathrm{~A}}$ mice. ${ }^{12}$ GluR2 is a subunit of the AMPA receptor, and the adenosine for the $Q / R$ site of its premRNA is converted to inosine (A-to-I conversion) by the action of adenosine deaminase acting on RNA 2 (ADAR2). Failure of A-to-I conversion at this site affects multiple AMPA receptor properties, including the $\mathrm{Ca}^{2+}$ permeability of the receptorcoupled ion channel. Inefficient GluR2 Q/R site editing is a disease-specific molecular dysfunction reported in the MNs of sporadic ALS patients. ${ }^{13}$

We have previously shown that oculomotor neurons resistant to the disease process in ALS show reduced AMPA-mediated inward calcium currents, and higher GABAmediated chloride currents, compared with spinal MNs that are vulnerable to the disease process. ${ }^{14}$ We have also demonstrated that knockdown of phosphatase and tensin homolog deleted on chromosome 10 (PTEN) via siRNA promotes MN survival in models of spinal muscular atrophy $(\mathrm{SMA})^{15}$ and ALS. ${ }^{16}$ Inhibition of PTEN attenuates the death of hippocampal neurons post injury by decreasing the effective translocation of the GluR2 subunit into the membrane. ${ }^{17}$ Leptin promotes GluR1 trafficking to hippocampal synapses via PTEN inhibition. ${ }^{18}$ Furthermore, PI3-kinase that is negatively regulated by $P T E N$ is required for maintaining AMPA receptor clustering at the postsynaptic membranes $^{19,20}$ and AMPA receptor surface expression. ${ }^{21}$ Thus, we speculate that manipulation of AMPA receptor expression and function by PTEN may represent a potential therapeutic strategy for clinical intervention in ALS. The breakthrough that human fibroblasts can be transformed into induced pluripotent stem (iPS) cells ${ }^{22}$ and these could then be differentiated into $\mathrm{MNs}^{23}$ opened new perspectives, providing a model of human origin for sporadic and familial cases of ALS. The aim of the present study is to establish a fibroblast-derived iPS-MN in vitro cell model for manipulation of AMPA receptor expression and function.

\section{Results}

Generation and characterization of human iPSCs (hiPSCs) from adult human dermal fibroblasts (HDFs). Under human research subject and stem cell protocols as approved by the institutional review boards, we recruited a healthy 40-year-old Chinese female to donate a skin biopsy to be used in reprogramming studies and the production of pluripotent stem cell lines. Three other healthy controls were also used to generate induced pluripotent stem cells (iPSCs) under ethical approval in the United Kingdom. The HDFs were isolated and plated under standard fibroblast conditions (Figure 1a). After four passages, the fibroblast identity in the resulting cell lines was confirmed by TE-7 antibody staining (Figure 1b). The cells were then used for generating iPS cells after infection with retroviruses containing human OCT3/4, SOX2, C-MYC and KLF4. As a control, we introduced green fluorescent protein (GFP) into HDF with pMXs-GFP retrovirus produced in PLAT-A packaging cells. More than $80 \%$ of HDF treated in this way expressed GFP (Figure 1c). Using this method, the dish was nearly covered with $>100$ granulated colonies $\sim 25$ days later. We observed distinct types of colonies that were flat and resembled hES cell-like colonies in between the granulated cells. At day 30, we picked 20 hES cell-like colonies and mechanically disaggregated them into small clumps without enzymatic digestion. The hES-like cells expanded on irradiated mouse embryonic fibroblasts (MEFs) using primate ES cell medium containing fibroblast growth factor-basic (bFGF).

To establish that reprogramming of the human fibroblasts had occurred, and that the putative hiPSCs were pluripotent, we evaluated their similarity to human embryonic stem cells (hESCs). Although we initially isolated 20 hiPSC clones, we focused on an in-depth characterization of only one of these clones. As illustrated in Figure 1d, the derived cells displayed the morphological characteristics of undifferentiated hESCs (i.e., large, compact, multicellular colonies of cells with a high nucleus-to-cytoplasm ratio) and showed high telomerase activity (Figures 1e and f). Moreover, they expressed several frequently used hESC markers (i.e., OCT3/4, SOX2, LIN28, NANOG, REX1) as shown by immunohistochemistry (Figure 1g) and reverse transcription-PCR (RT-PCR; Figure 1h). In addition, the putative hiPSC line also maintained a normal karyotype (Figure 1i). The colonies continued to passage after at least 6 months by passaging once a week. The split ratio was $1: 3$ to $1: 6$. Bisulfite genomic sequencing analyses evaluating the methylation status of cytosine guanine dinucleotides $(\mathrm{CpG})$ in the promoter region of the pluripotent-associated gene Oct4 revealed that this was highly unmethylated, whereas the CpG dinucleotides of the region were highly methylated in parental HDF (Figure 1j). These findings indicate that this promoter is active in hiPSCs.

To test pluripotency in vivo, we transplanted human iPS cells subcutaneously into the hind limb muscle of NOD/SCID mouse. At 8 weeks after injection, we observed tumor formation. Histological examination showed that the tumor contained various tissues: neural tissues (ectoderm, Figure 1k), cartilage (mesoderm, Figure 1l), muscle (mesoderm, Figure $1 \mathrm{~m}$ ) and primitive gut (endoderm, Figure 1n). 

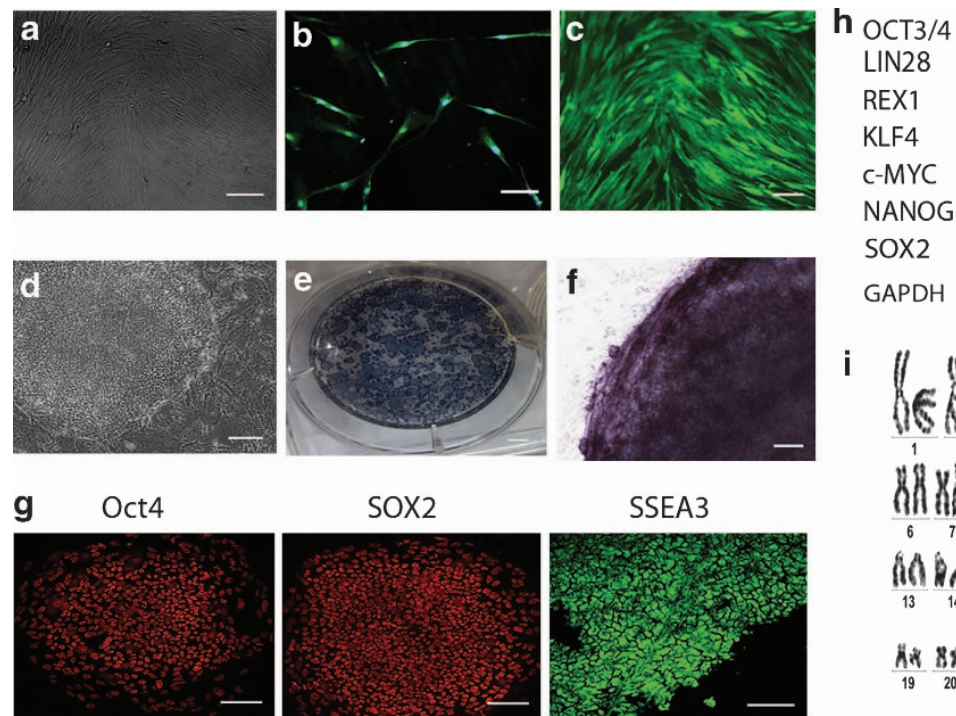

Tra1-81

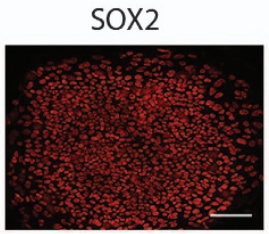

Tra1-60
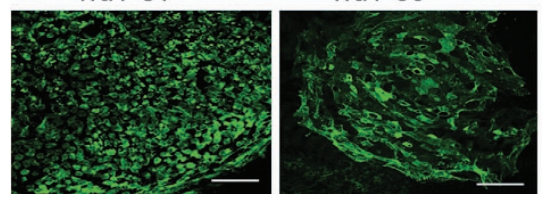

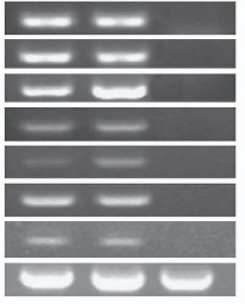

GAPDH

1

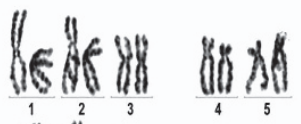

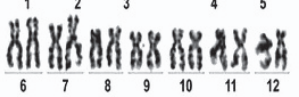

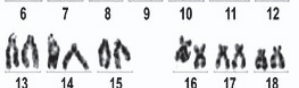
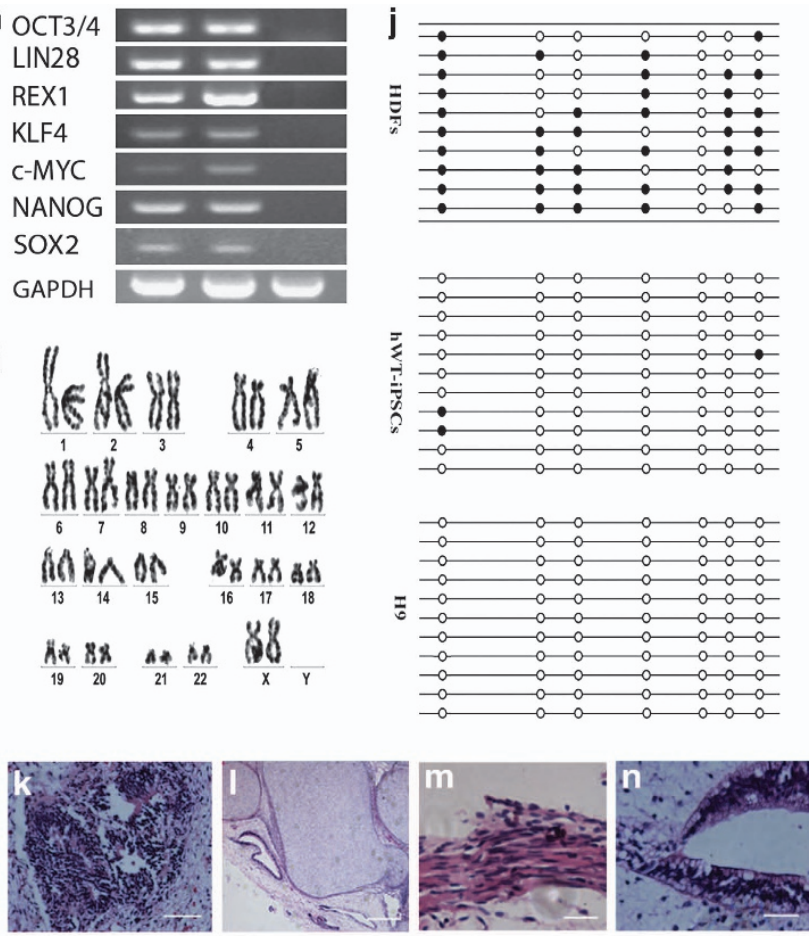

Figure 1 Characterization of human dermal fibroblasts used for hiPSC induction. (a) Culture of human dermal fibroblasts (bar $=50 \mu \mathrm{m}$ ). (b) TE-7 immunostaining confirmed that the resulting cultures were of fibroblast identity $(\mathrm{bar}=100 \mu \mathrm{m})$. (c) Phase contrast image of human dermal fibroblasts transfected with GFP retroviruses $(\mathrm{bar}=100 \mu \mathrm{m})$. (d) The $\mathrm{hESC}$-like hiPS colony $(\mathrm{bar}=50 \mu \mathrm{m})$. (e and f) These $\mathrm{hESC}$-like colonies showed high alkaline phosphatase expression $(\mathrm{bar}=50 \mu \mathrm{m})$. (g) Immunocytofluorescence of the hiPSCs showing the expression of multiple hESC markers (bar $=100 \mu \mathrm{m}$ ). (h) RT-PCR analysis of hESC marker genes in hiPSCs. (i) No karyotypic abnormalities were observed in the hiPSCs. (j) Open circles indicate unmethylated CpG dinucleotides, whereas closed circles indicate methylated CpGs in the promotor of Oct4. After transplantation into the hind limb muscle of NOD/SCID mice, hiPSCs generated teratomas showing (k) neural tissue (ectoderm; bar $=100 \mu \mathrm{m}$ ), (I) cartilage (mesoderm; bar $=100 \mu \mathrm{m}),(\mathrm{m})$ muscle (mesoderm; bar $=100 \mu \mathrm{m})$ and $(\mathbf{n})$ primitive gut (endoderm; bar $=100 \mu \mathrm{m})$

Taken together, these data demonstrate that reprogramming of wild-type fibroblasts to a pluripotent state had successfully occurred.

MN differentiation of hiPSCs. Several groups have devised protocols to differentiate hESCs/hiPSCs to functional MNs. ${ }^{23-25}$ Here we chose a protocol that follows the principles of normal development and leads to a high efficiency in the production of the target MNs (Figure 2a). We raised hiPSCs in co-culture with a MEF feeder layer, as previously described. The cultures were raised to $80-90 \%$ confluence and exhibited a uniform undifferentiated phenotype to achieve neuro-ectodermalization before inducing them to form embryoid bodies (EBs) in suspension cultures. EB aggregates are usually grown as free-floating spheres. The EBs were cultured for 7 days and then they were attached to tissue culture dishes to initiate the differentiation of neuroepithelial cells that soon emerge as neural epithelial rosettes. After 3 days, the primitive neural epithelial cells formed and expressed anterior transcription factors, such as PAX6 and OTX2 (Figure 2b). After an additional 5 days in the presence of retinoic acid (RA), definitive neuroepithelial cells tended to form neural tube-like rosettes. The neural rosettes were gently blown off and treated with both RA and sonic hedgehog $(\mathrm{SHH})$, resulting in the appearance of $\mathrm{MN}$ progenitors. These cells then differentiated to spinal MNs in week 5 and expressed transcription factors, such as Islet1/2
(Figure 2c). This protocol generated $\sim 50 \%$ of Islet $1 / 2$ expressing MNs from the original hWT-iPSC cells. These MNs, when further cultured in the presence of neurotrophic factors, extend long axonal projections, express choline acetyltransferase (ChAT; Figure 2d) and become electrophysiologically active.

PTEN knockdown increases phosphorylation of Akt and Bad in primary cultured MNs and iPS-derived MNs. The tumor suppressor protein PTEN is a member of the protein tyrosine phosphatase family that can negatively regulate the serine/threonine kinase Akt to exert its tumor suppressor function. ${ }^{26}$ The protein phosphatase activity of PTEN can regulate cell migration, spreading and growth. ${ }^{27}$ PTEN is widely expressed in the mouse CNS and preferentially in neurons such as large pyramidal neurons. ${ }^{28}$ PTEN localizes to both the nucleus and cytoplasm of neuronal and glial cells. ${ }^{28-30}$ Significant progress has been made in investigating the broader role of PTEN in the brain. In addition to its normal functions such as control of neuronal migration ${ }^{31,32}$ and neuronal size, ${ }^{33,34}$ the PTEN protein is involved in pathological processes surrounding neuronal injury such as those associated with brain ischemia, neurological and mental disorders and drug addiction. ${ }^{33-39}$ Conditional inactivation of PTEN leads to behavioral abnormalities and neuropathological changes characterized by neuronal hypertrophy. ${ }^{39}$ Park et al. ${ }^{40}$ reported that modulation of the 

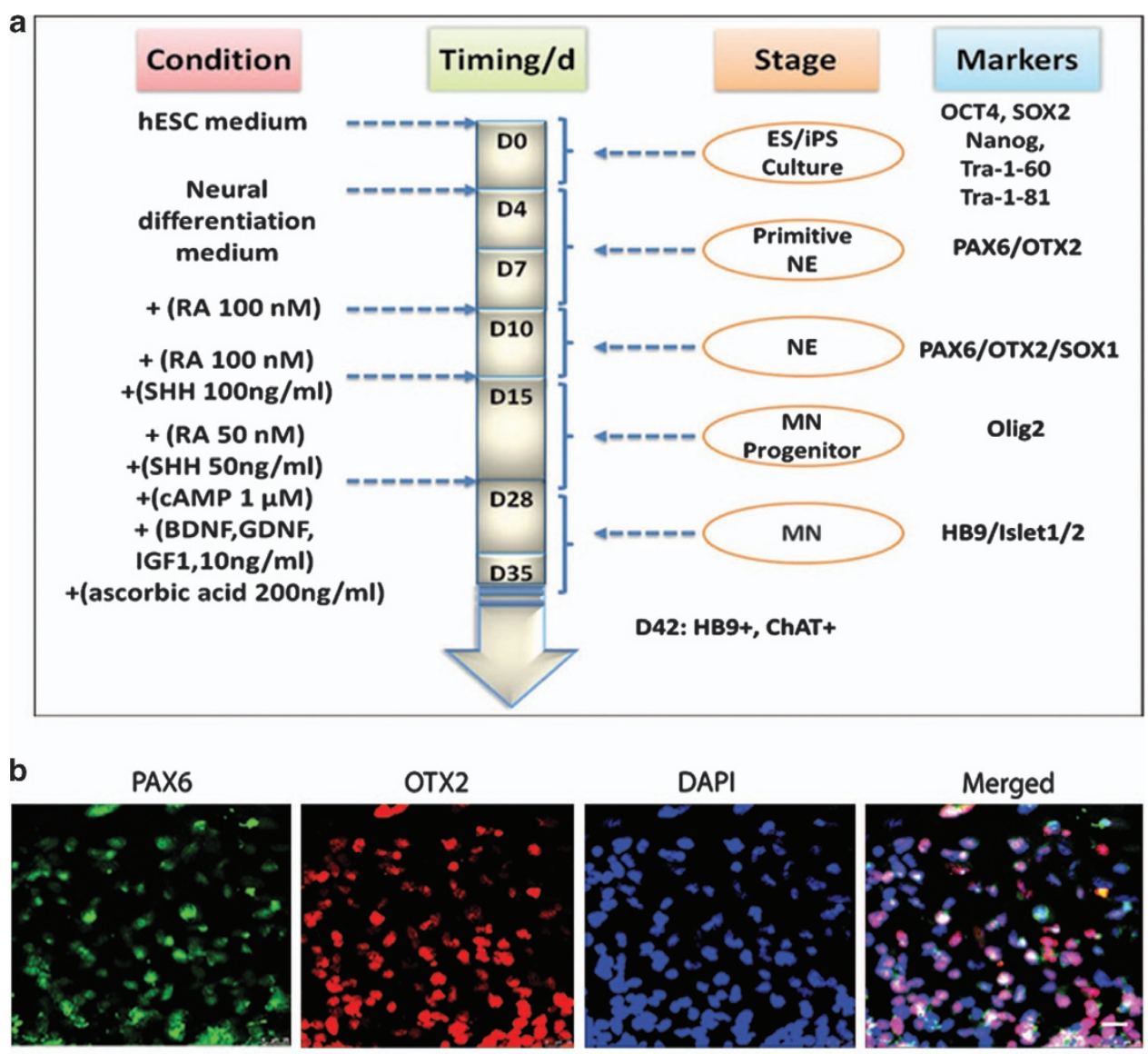

c
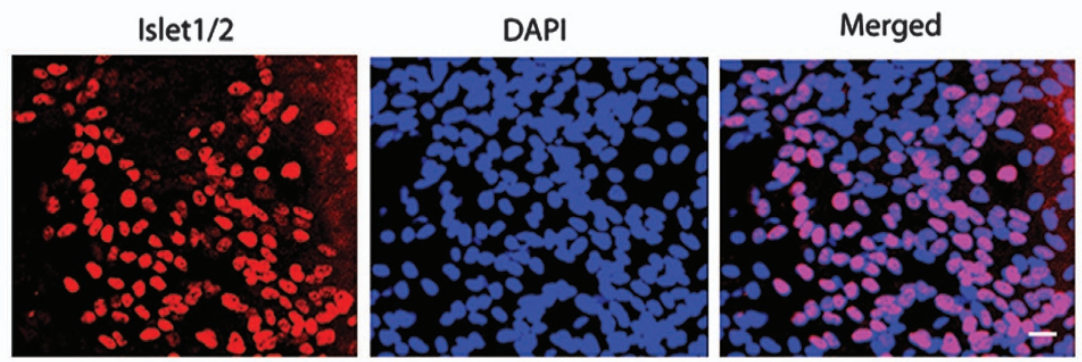

d
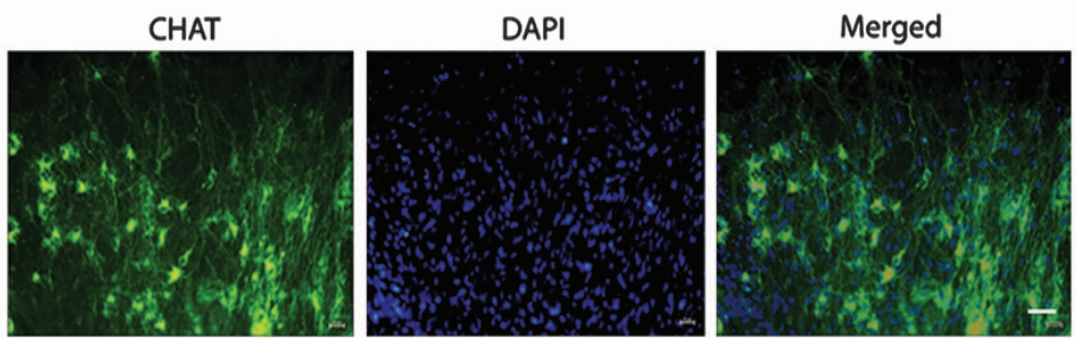

Figure 2 Generation and characterization of spinal motor neurons from hiPSCs. (a) Schematic drawing of the experimental setup and strategy to derive induced spinal motor neurons. (b) When differentiated for 12 days, the hiPSC-derived primitive neuroepithelial cells are positive for OTX2 (red) and PAX6 (green), bar $=25 \mu \mathrm{m}$. (c) When differentiated for 35 days, the hiPSC-derived motor neurons are positive for Islet $1 / 2$ (red), bar $=50 \mu \mathrm{m}$. (d) When differentiated for 45 days, hiPSC-derived motor neurons become mature, and are positive for ChAT (green), bar $=50 \mu \mathrm{m}$. DAPI shown as blue denotes DAPI-stained nuclei

PTEN/mTOR pathway promotes axon regeneration in the adult CNS. To assess whether PTEN can be manipulated in iPS-derived MNs, PTEN was suppressed via siRNA in primary cultured and iPS-derived MNs. This resulted in decreased PTEN expression as assessed by immunofluorescence staining (Figures $3 a$ and e) and western blotting (Figures $3 \mathrm{~b}$ and $\mathrm{f}$ ). Phosphorylation of Akt and Bad was increased following PTEN knockdown (Figures $3 c, d, g$ and h). 

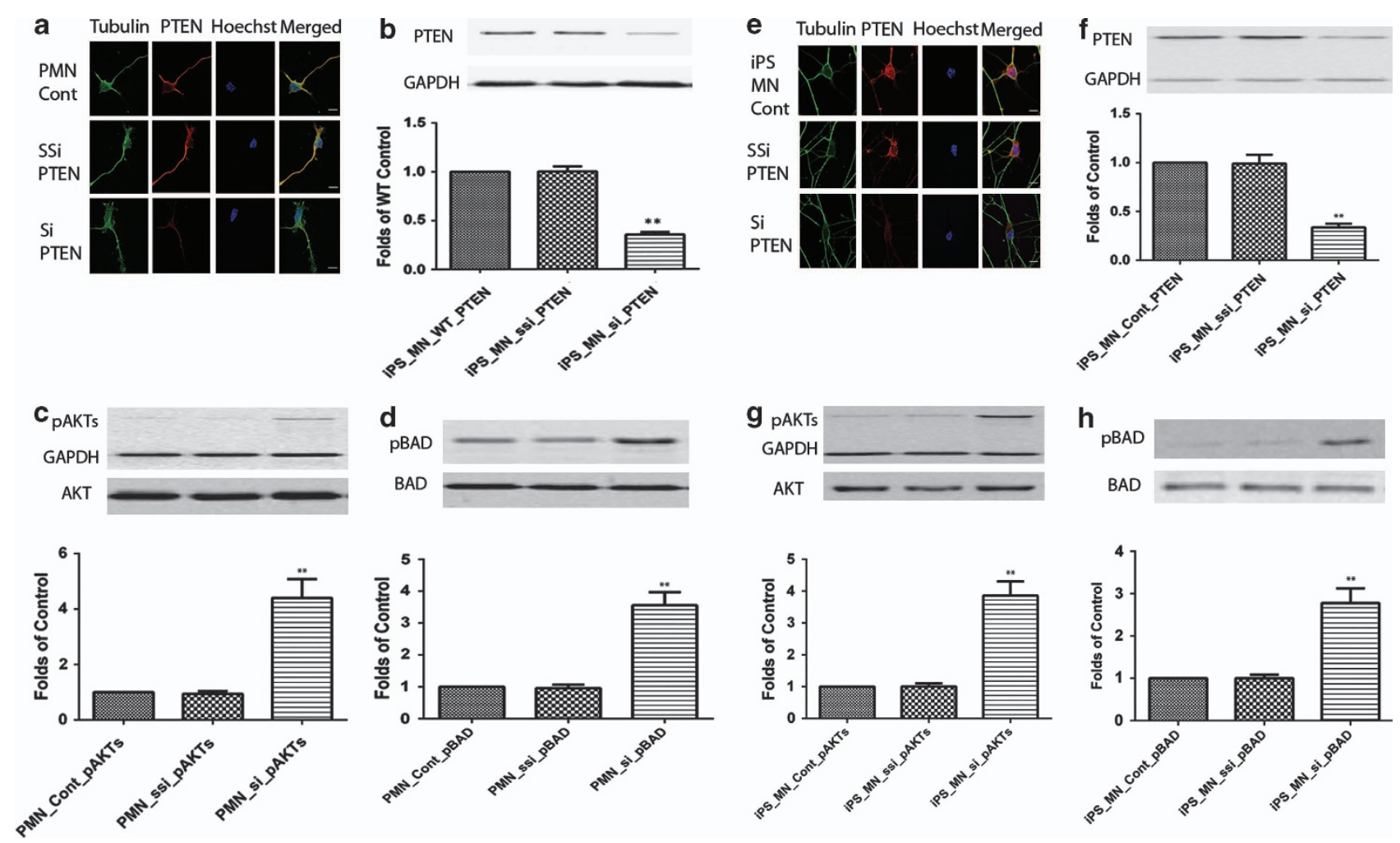

Figure 3 PTEN knockdown ( $\mathbf{b}$ and $\mathbf{f}$ ) increases phosphorylation of AKT ( $\mathbf{c}$ and $\mathbf{g}$ ) and Bad ( $\mathbf{d}$ and $\mathbf{h}$ ) in primary cultured motor neurons and iPS-derived motor neurons. Primary (a) or iPS-derived (e) motor neurons were immunostained with anti-tubulin (green), Hoechst (nuclear staining in blue) and PTEN (red). Scale bar, $20 \mu$ m. Western blotting on homogenates from primary cultured (b-d) and iPS-derived motor neurons. PTEN is normalized by GAPDH (b and $\mathbf{f}$ ) and pAKT is normalized by AKT (c and $\mathbf{g}$ ). pBAD is normalized by BAD ( $\mathbf{d}$ and $\mathbf{h}$ ). Results represent the mean + S.E.M. from four independent experiments. ${ }^{* *} P<0.01$, tested by one-way ANOVA

This is consistent with our previous report ${ }^{15}$ in primary cultured wild-type and SMA MNs.

PTEN knockdown decreases AMPA receptor expression in primary cultured and iPS-derived MNs. The selective vulnerability of MNs to AMPA receptor-mediated excitotoxicity can be studied in vitro using purified MNs. These MNs are sensitive to AMPA- or kainate-induced excitotoxicity. ${ }^{41}$ AMPA- or kainate-induced MN death can be inhibited by NBQX, an AMPA receptor antagonist. ${ }^{42}$ In this study, we investigate the potential effects of PTEN on MN excitability in primary cultured and iPS-derived MNs. The first step was to assess whether PTEN knockdown has an effect on AMPA receptor expression. Here we showed that PTEN knockdown decreased GluR1 and GluR2 expression in primary cultured MNs (Figures $4 \mathrm{a}-\mathrm{c}$ ) and iPS-derived MNs (Figures 4g-j). GluR3 was decreased in iPS-derived MNs (Figure 4k), but not in primary cultured MNs (Figure 4e). There was no significant change in GluR4 expression in primary cultured MNs (Figure 4f) or iPS-derived MNs (Figure 4I) at 7 days post viral transfection.

PTEN knockdown decreases AMPA-induced whole-cell currents in primary cultured and iPS-derived MNs. Based on the decrease of expression of AMPA receptors following PTEN silencing, we next tested the effects of PTEN knockdown on the functional output of AMPA receptors in primary cultured and iPS-derived MNs.
Whole-cell patch-clamp recording was performed to examine the effects of PTEN knockdown on the electrophysiological properties of primary cultured and iPS-derived MNs. Dose responses of AMPA-induced whole-cell currents were recorded in $20 \mathrm{mM}$ extracellular $\mathrm{Na}+$ at $-60 \mathrm{mV}$, in response to AMPA concentrations ranging from $5 \mu \mathrm{M}$ to $5 \mathrm{mM}$. Each point represents mean \pm S.E.M. from three cells. Average peak amplitudes were $24 \pm 6 \mathrm{pA}(5 \mu \mathrm{M})$, $295 \pm 63 \mathrm{pA}(50 \mu \mathrm{M}), 422 \pm 58 \mathrm{pA}(500 \mu \mathrm{M})$ and $399 \pm 34 \mathrm{pA}$ $(5 \mathrm{mM})$ in control primary cultured MNs; $28 \pm 3 \mathrm{pA}(5 \mu \mathrm{M})$, $298 \pm 35 \mathrm{pA}(50 \mu \mathrm{M}), 362 \pm 50 \mathrm{pA}(500 \mu \mathrm{M})$ and $404 \pm 34 \mathrm{pA}$ $(5 \mathrm{mM})$, respectively, in scramble siPTEN primary cultured MNs; $12 \pm 3 \mathrm{pA}(5 \mu \mathrm{M}), 138 \pm 41 \mathrm{pA}(50 \mu \mathrm{M}), 227 \pm 53 \mathrm{pA}$ $(500 \mu \mathrm{M})$ and $278 \pm 32 \mathrm{pA}(5 \mathrm{mM})$, respectively, in siPTEN primary cultured MNs. PTEN knockdown decreases AMPAinduced whole-cell currents in primary cultured MNs in a dose-dependent manner $\left(n=3,{ }^{*} P<0.05,{ }^{* \star} P<0.01\right.$, tested by one-way ANOVA). Similarly, average peak amplitudes were $25 \pm 7 \mathrm{pA}(5 \mu \mathrm{M}), 272 \pm 58 \mathrm{pA}(50 \mu \mathrm{M})$, $359 \pm 58 \mathrm{pA}(500 \mu \mathrm{M})$ and $389 \pm 22 \mathrm{pA}(5 \mathrm{mM})$, respectively, in control iPS-derived MNs; $22 \pm 8 \mathrm{pA}(5 \mu \mathrm{M}), 267 \pm 49 \mathrm{pA}$ $(50 \mu \mathrm{M}), 352 \pm 55 \mathrm{pA}(500 \mu \mathrm{M})$ and $402 \pm 76 \mathrm{pA}(5 \mathrm{mM})$, respectively, in scramble siPTEN iPS-derived $\mathrm{MNs}$; $13 \pm 3 \mathrm{pA}(5 \mu \mathrm{M}), 130 \pm 38 \mathrm{pA}(50 \mu \mathrm{M}), 237 \pm 26 \mathrm{pA}(500 \mu \mathrm{M})$ and $262 \pm 42 \mathrm{pA}(5 \mathrm{mM})$, respectively, in siPTEN iPS-derived MNs. PTEN knockdown decreases AMPA-induced wholecell currents in iPS-derived MNs in a dose-dependent manner $\left(n=3,{ }^{*} P<0.05,{ }^{\star \star} P<0.01\right.$, tested by one-way 


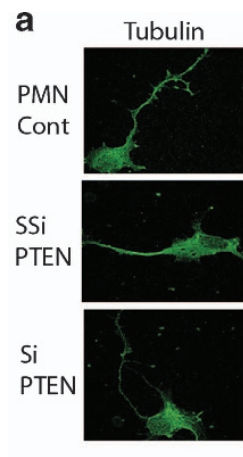

b

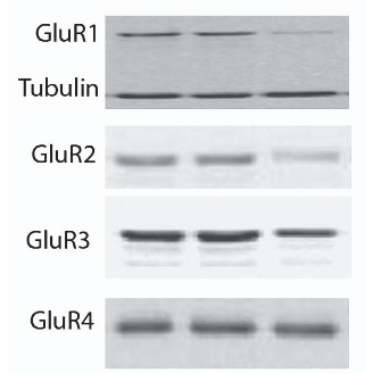

GluR1
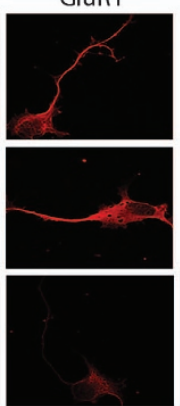

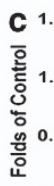
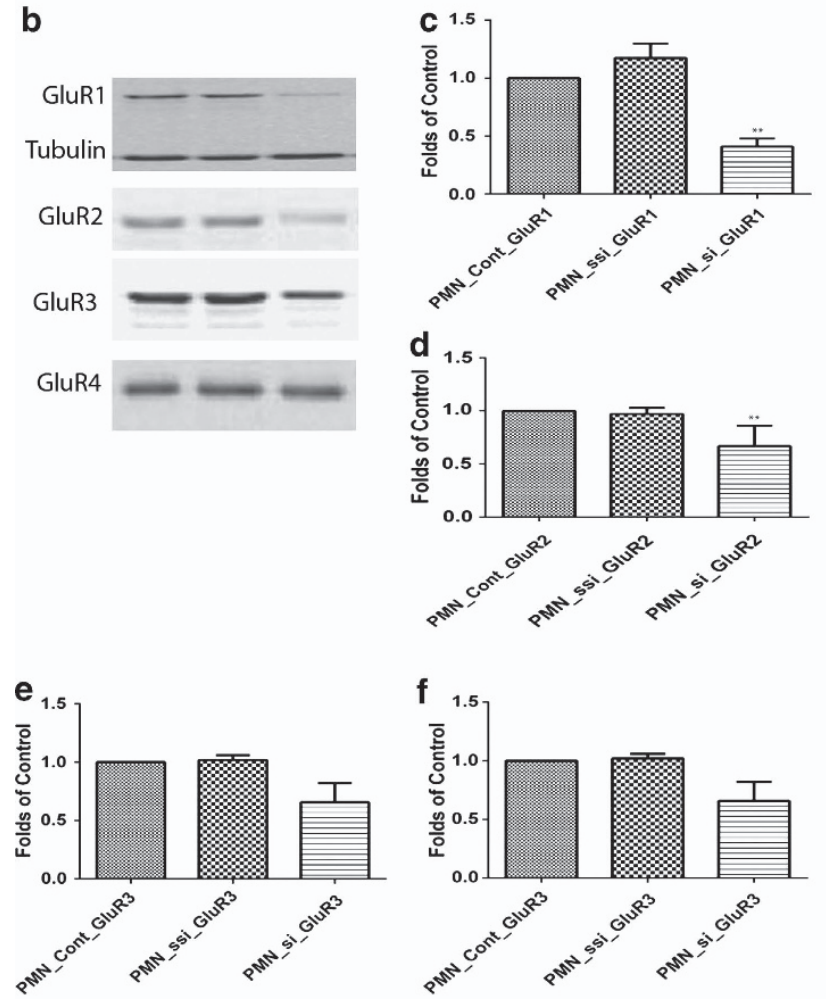

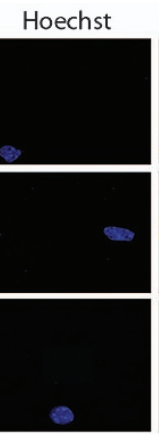

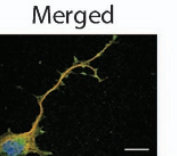
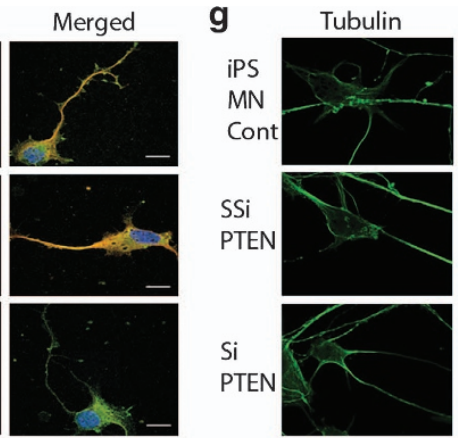

h
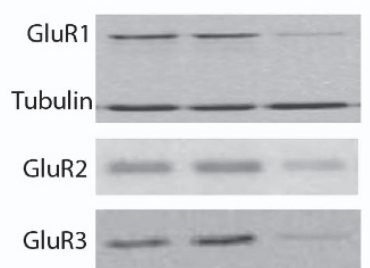

GluR4

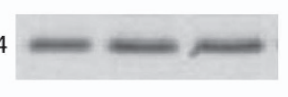

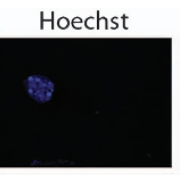
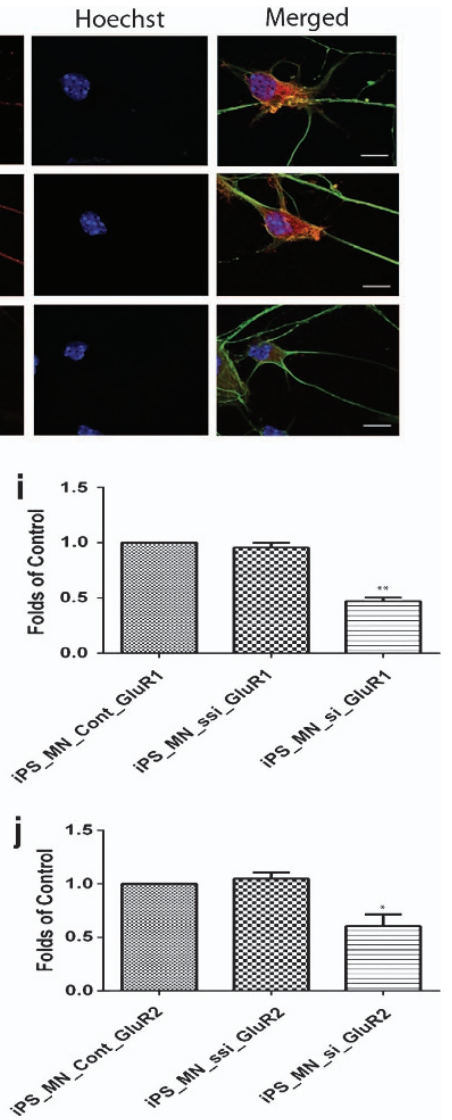

k

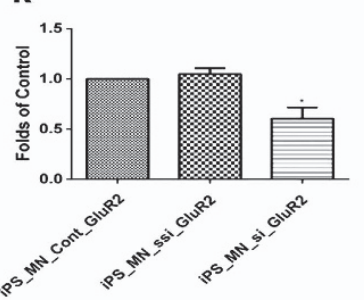

I

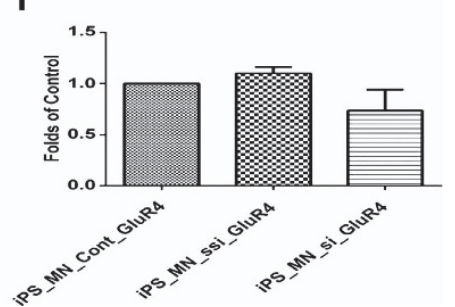

Figure 4 PTEN knockdown decreases AMPA receptor expression in primary cultured (a-f) and iPS-derived ( $\mathbf{g}-\mathbf{I})$ motor neurons. Motor neurons were immunostained with anti-tubulin (green), Hoechst (nuclear staining in blue) and AMPA receptor (GluR1, red). Scale bar, $20 \mu \mathrm{m}$. (b-f and h-I) Western blotting. PTEN knockdown decreases GluR1 (c and i) and GluR2 (d and j) but not GluR4 expression in both primary cultured and iPS-derived MNs. GluR3 decreases significantly in iPS-derived MNs (k) but not in primary cultured MNs (e). Results represent the mean + S.E.M. from four independent experiments. ${ }^{* *} P<0.01$, tested by one-way ANOVA

ANOVA). The $\mathrm{EC}_{50}$ values estimated from fits to pooled data were $106 \mu \mathrm{M}$ for primary cultured MNs and $113 \mu \mathrm{M}$ for iPSderived MNs (Figures $5 \mathrm{~d}$ and $\mathrm{h}$ ). Average peak AMPAinduced whole-cell currents were recorded in $\mathrm{Na}+$-free extracellular solution containing $50 \mathrm{mM} \mathrm{Ca}^{2+}$ at $-60 \mathrm{mV}$ in primary cultured and iPS-derived MNs, evoked by AMPA $100 \mu \mathrm{M}(n=8)$. AMPA at $100 \mu \mathrm{M}$ was close to the $\mathrm{EC}_{50}$ from the dose-response recordings for primary cultured MNs (Figure 5c) and iPS-derived MNs (Figure 5g). Topical application with $100 \mu \mathrm{M}$ AMPA elicited a mean amplitude of whole-cell current in control $(431 \pm 156 \mathrm{pA}(n=8))$, scramble SIPTEN $(401 \pm 126 \mathrm{pA}(n=8))$ and siPTEN $(198 \pm 59 \mathrm{pA}$ $(n=8))$, respectively, in primary cultured MNs and iPSderived MN control $(471 \pm 82 \mathrm{pA}(n=8))$, scramble siPTEN $(437 \pm 96 \mathrm{pA} \quad(n=8))$ and siPTEN $(208 \pm 69 \mathrm{pA} \quad(n=8))$, respectively. PTEN knockdown by siRNA significantly decreased AMPA-induced whole-cell currents in primary cultured and iPS-derived MNs $(P<0.01)$.

PTEN knockdown decreases AMPA-induced cell death in primary cultured and iPS-derived MNs. AMPA receptor trafficking plays a role in regulating excitatory synaptic strength and multiple growth factors, and hormones modulate this process. ${ }^{43}$ The effects of leptin on GluR1 trafficking involve an increase in Ptdlns(3,4,5)P3 levels secondary to PTEN inhibition as the effects of leptin on surface GluR1 staining were associated with increased Ptdlns $(3,4,5) \mathrm{P} 3$ levels and elevation in Ptdlns $(3,4,5) \mathrm{P} 3$ levels occurred before altered GluR1 trafficking. Inhibitors of PI3-kinase attenuated the effects of leptin on surface GluR1 and 

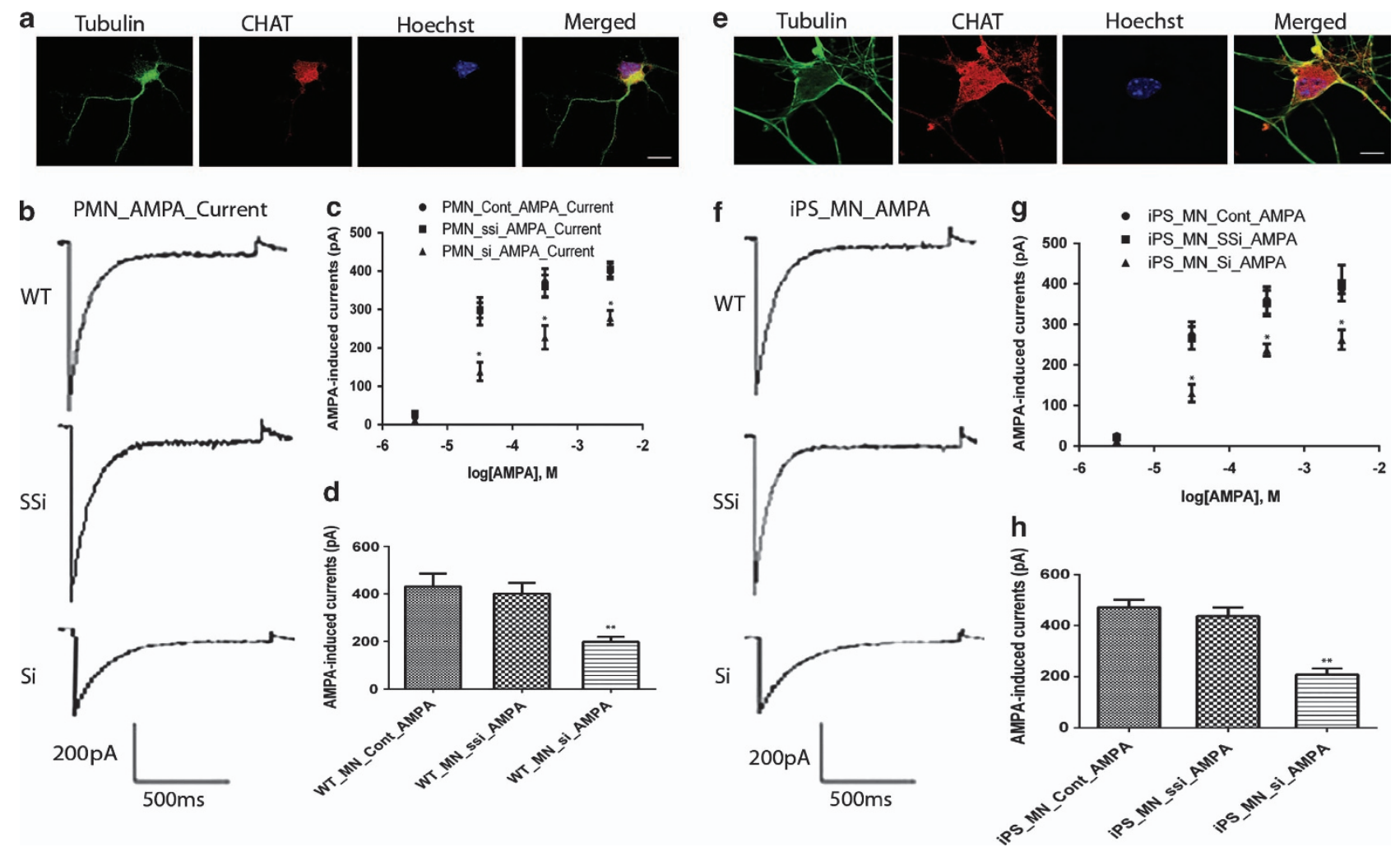

Figure 5 PTEN knockdown decreases AMPA-induced whole-cell currents in primary cultured (a-d) and iPS-derived (e-h) motor neurons. Primary cultured (a) and iPSderived (e) motor neurons were immunostained with anti-tubulin (green), Hoechst (nuclear staining in blue) and ChAT (red). Scale bar, $20 \mu \mathrm{m}$. (b and f) Representative current traces elicited by AMPA. (c and g) Dose response of AMPA-induced whole-cell currents were recorded in $20 \mathrm{mM}$ extracellular $\mathrm{Na}+$ at $-60 \mathrm{mV}$, in response to AMPA concentrations ranging from $5 \mu \mathrm{M}$ to $5 \mathrm{mM}$. Each point represents the mean \pm S.E.M. from three cells $\left({ }^{*} P<0.05,{ }^{* *} P<0.01\right.$, tested by one-way ANOVA). EC 50 values estimated from fits to pooled data were $106 \mu \mathrm{M}$ for primary cultured motor neurons and $113 \mu \mathrm{M}$ for iPS-derived neurons. (d and $\mathbf{h}$ ) Average peak AMPA-induced whole-cell currents were recorded in $\mathrm{Na}+$-free extracellular solution containing $50 \mathrm{mM} \mathrm{Ca}^{2+}$ at $-60 \mathrm{mV}$ in primary cultured and iPS-derived motor neurons, evoked by AMPA $100 \mu \mathrm{M}$ $(n=8)$. Columns represent the peak amplitudes of agonist-induced whole-cell currents. Results represent the mean + S.E.M. from four independent experiments, with 8 motor neurons of each $\left({ }^{*} P<0.05,{ }^{* *} P<0.01\right.$, tested by one-way ANOVA)

Ptdlns(3,4,5)P3 levels, consistent with PI3-kinase-dependent signaling underlying these effects. ${ }^{44}$ Alterations in Ptdlns $(3,4,5) \mathrm{P} 3$ levels may promote structural rearrangement of the actin cytoskeleton that in turn influences the synaptic density of AMPA receptors. ${ }^{45} \mathrm{MNs}$ are thought to be vulnerable to excessive AMPA receptor stimulation because of the presence of a high number of GluR2-lacking AMPA receptors. Low GluR2 levels yield AMPA receptors with a high $\mathrm{Ca}^{++}$permeability. ${ }^{46-49}$ A downregulation of GluR2 expression preceding neurodegeneration has never been observed. However, relatively low GluR2 expression is likely to contribute to the selective vulnerability of MNs to AMPA receptor stimulation. It has been recently reported that toxic factors released from glial cells expressing $\mathrm{mt}$ SOD1 contribute to the MN toxicity. ${ }^{50,51}$ To determine whether downregulation of AMPA receptor expression can contribute to MN survival, we used the TUNEL (terminal deoxynucleotidyl transferase dUTP nick end labeling) assay to assess apoptotic cell death in primary cultured and iPS-derived MNs. Cells were treated with $50,100,200,300,400,500$ and $600 \mu \mathrm{M}$ (S)-AMPA to determine dose-response effects of AMPA exposure. In control primary cultured MNs, $5.1 \pm 1.6 \%, \quad 8.1 \pm 2.3 \% \quad(50 \mu \mathrm{M}), \quad 11.5 \pm 2.1 \% \quad(100 \mu \mathrm{M})$, $21.0 \pm 3.7 \%(200 \mu \mathrm{M}), \quad 48.4 \pm 9.7 \% \quad(300 \mu \mathrm{M}), \quad 59.1 \pm 9.7 \%$
$(400 \mu \mathrm{M}), 66.6 \pm 12.5 \%(500 \mu \mathrm{M})$ and $70.5 \pm 8.7 \%(500 \mu \mathrm{M})$ TUNEL-positive cells were seen, respectively. Exposure to $300 \mu \mathrm{M}$ AMPA resulted in the death of $\sim 50 \%$ of the MNs and this was inhibited by the AMPA receptor inhibitor (cyano-7nitroquinoxaline-2,3-dione (CNQX; Figure 6). PTEN knockdown significantly reduced cell death in primary cultured MNs (control $48.8 \%$, scramble $44.1 \%$ and siPTEN $25.2 \%$, respectively) and iPS-derived MNs (Control 50.5\%, scramble $48.9 \%$ and siPTEN $27.9 \%$, respectively) (Figure 6).

\section{Discussion}

The aim of the present study was to determine whether PTEN knockdown has an effect on functional AMPA receptor expression and AMPA-mediated cell death in primary cultured and iPS-derived MNs. AMPA receptors are heteromeric complexes composed of various combinations of the four subunits: GLUR1 to GLUR4. The presence of the GLUR2 subunit in the assembled AMPAR determines its calcium permeability, and alternative flip or flop splicing of all subunits generates further diversity affecting the kinetic properties of AMPAR. ${ }^{43,44}$ MNs are more susceptible to AMPA receptormediated death compared with other spinal neurons. ${ }^{47,48}$ Deactivation and desensitization kinetics of AMPA receptors 

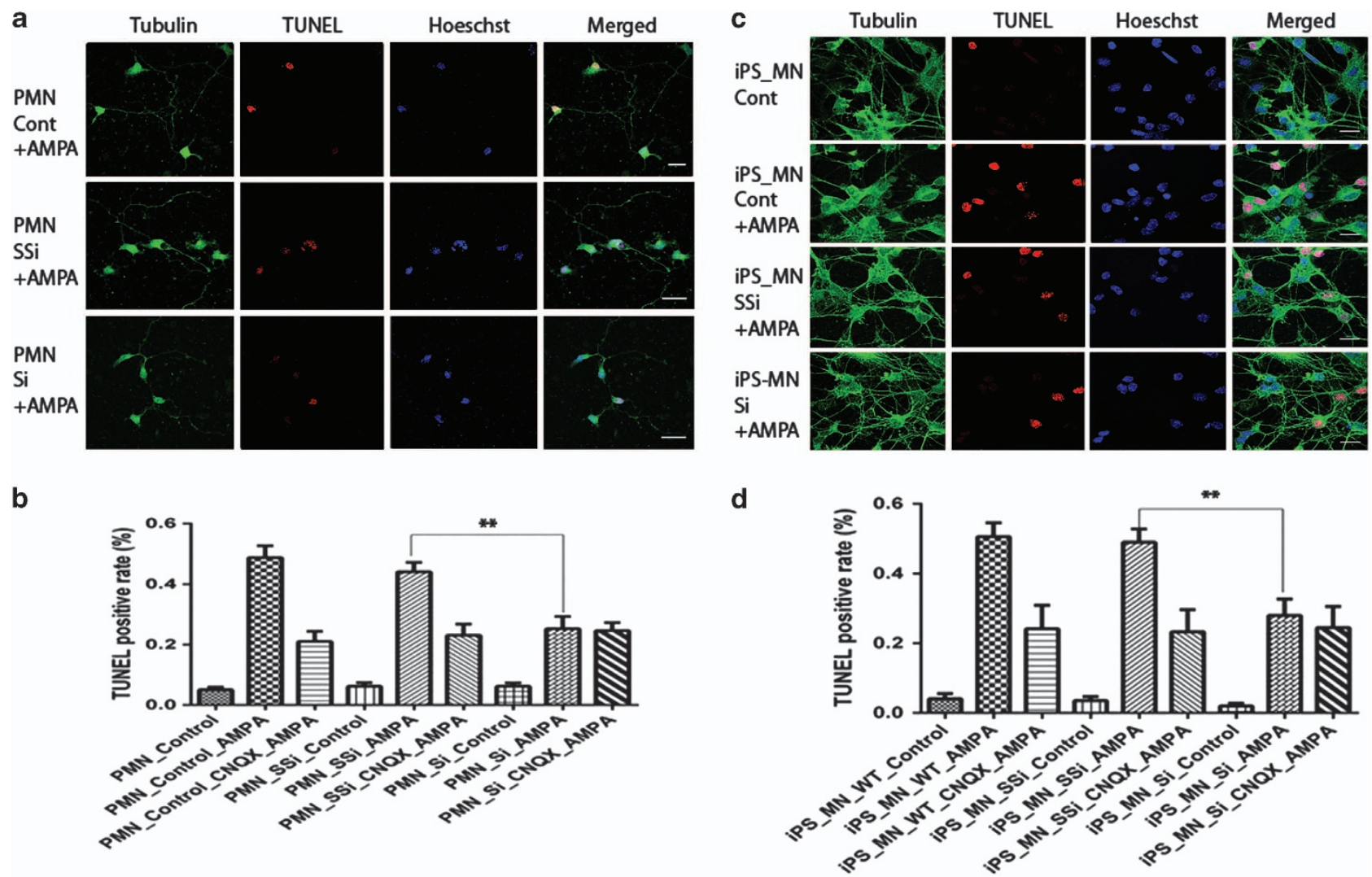

Figure 6 PTEN knockdown decreases AMPA-induced cell death in primary cultured and iPS-derived motor neurons. Primary cultured (a) and iPS-derived (c) motor neurons were immunostained with anti-tubulin (green), Hoechst (nuclear staining in blue) and TUNEL staining (red). Scale bar, $20 \mu \mathrm{m}$. (b and d) Results represent the mean + S.E.M. from four independent experiments. ${ }^{* \star} P<0.01$, tested by one-way ANOVA

in MNs also resembled AMPA receptor kinetics in cerebellar Purkinje neurons. ${ }^{47}$ Activation of PI3-kinase is required for AMPA receptor insertion during long-term potentiation (LTP) of mEPSCs in cultured hippocampal neurons. ${ }^{44}$ Although the molecular control of AMPA receptor kinetics is complex and incompletely understood, subunit composition appears to be an important determinant of AMPA receptor desensitization. ${ }^{52}$

To assess functional AMPA receptors in primary cultured and iPS-derived MNs, we measured AMPA receptormediated current in both types of cells. PTEN knockdown decreased GluR1 and GluR2 expression and AMPA-induced whole-cell currents. Downregulation of GluR1 was more significant than of GluR2. Our findings appear to imply that the ratio of GluR1 and GluR2 changes following PTEN knockdown may cause variation in the AMPA receptor properies of calcium permeability and excitatory synaptic transmission. It has been reported that the antiglutamate drug, riluzole, is able to modulate AMPA receptors by reducing the kainate-induced currents in spinal MNs in a noncompetitive and a dose-dependent manner. AMPA is considered to play an important role in the selective death of MNs in ALS. A significantly different ratio between inhibitory and excitatory synapses was present in MNs from the SOD1 ${ }^{\text {G93A }}$ mouse. ${ }^{11}$ The levels of the GluR2 AMPA subunit are decreased in spinal MNs before symptom onset in SOD1 ${ }^{\text {G93A }}$ mice. $^{12}$ Inefficient GluR2 Q/R site editing appears to be a disease-specific molecular alteration reported in sporadic ALS patients. ${ }^{13}$ At the level of the glutamatergic synapse, high concentrations of riluzole have been reported to inhibit glutamate release, attenuate excitatory amino acid receptor activation and decrease excitability of the postsynaptic cell membrane. ${ }^{52}$ The high concentrations required, however, are unlikely to be reached in vivo using clinically approved doses. AMPA receptors are glutamate-gated cation selective channels that mediate most fast excitatory synaptic transmission in the mammalian brain. AMPA receptor desensitization protects neurons against excitotoxic effects resulting from prolonged activation, as suggested by the pharmacological blockade of AMPAR desensitization that enhances excitotoxicity in neurons, including spinal MNs. ${ }^{10,46-49,52}$ Here we report that PTEN inhibition decreases AMPA-induced cell death in primary cultured and iPS-derived MNs by downregulation of AMPA receptor expression and function assessed by AMPA-mediated whole-cell currents.

We have previously reported that oculomotor neurons resistant to the disease process in ALS show reduced AMPAmediated inward calcium current compared with spinal MNs that are vulnerable to the disease process. ${ }^{10}$ These data implied that downregulation of AMPA receptor expression in spinal MNs might increase their resistance to exctitotoxic injury. We previously showed that PTEN depletion increased MN survival in models of SMA and ALS. ${ }^{15,16}$ Here we show that PTEN inhibition decreases AMPA-mediated inward currents. Thus, PTEN depletion or inactivation may represent 
a therapeutic or neuroprotective strategy for AMPA receptormediated MN death.

It has been reported that reduction of kainate-induced currents by riluzole is consistent with its neuroprotective effects, because it hyperpolarizes the membrane and attenuates spike-firing rates, leading to reduced presynaptic glutamate release. However, riluzole has a limited effect in the clinical setting because the high concentrations required to achieve these effects are unlikely to be reached in vivo using clinically approved doses. ${ }^{53}$ PTEN silencing may achieve amelioration of AMPA receptor-mediated toxicity in vivo. Indeed, PTEN depletion has been shown to dramatically increase MN survival in vivo. ${ }^{15}$

We have observed that the results obtained from iPS-derived and primary cultured MNs are mostly but not always consistent; for example, GluR3 decreases significantly in iPS-derived MNs (Figure 4k) but not in primary cultured MNs (Figure 4e). We used the best PTEN shRNA sequence from multiple tested sequences for the lentiviral constructs for the transduction of primary MNs. This siRNA has been tested in neuronal cell lines $^{38,54}$ and MNs in vitro ${ }^{16}$ and in vivo. ${ }^{15}$ The PTEN siRNA virus we used for iPS-derived MNs was purchased from Santa Cruz Biotechnology Inc. (Dallas, TX, USA), which has been fully characterized by the company, and its efficiency of PTEN knockdown has been tested widely by various research groups. ${ }^{55,56}$ As both the cells and the siRNA virus are different, it would be possible to have variation for GluR3 knockdown between primary cultured and iPS-derived MNs. This difference is unlikely to represent off-target effects. We have not seen significant PTEN knockdown using scrambled siRNA sequences and other siRNA sequences. ${ }^{15,16,54-56}$ We believe therefore that the PTEN knockdown is specific in both primary cultured and iPS-derived MNs.

In conclusion, we have shown for the first time that PTEN knockdown decreases the expression and activity of AMPA receptors in MNs. Modulation of AMPA receptors may underlie some of the neuroprotective effects of PTEN inhibition or reduced expression of the PTEN protein. In future work, we will use ALS patient fibroblasts to generate iPS-derived MNs and investigate the effect of PTEN knockdown on MN survival in patient iPS-derived MNs from specific subtypes of ALS patients. This may represent a useful strategy for drug screening to identify compounds that may modulate disorders involving neuronal hyperexcitability, including ALS.

\section{Materials and Methods}

Human fibroblast and Plat-A culture. Under human research subject and stem cell protocols as approved by the institutional review boards, we recruited a healthy 40-year-old Chinese female to donate a skin biopsy to be used in reprogramming studies and the production of pluripotent stem cell lines. Three other healthy controls were also used to generate iPSCs under ethical approval in the United Kingdom. The dermal fibroblasts were isolated by $0.25 \%$ trypsin (Gibco, Shanghai, China, 25200). HDFs and Plat-A cells were maintained in medium containing Dulbecco's modified Eagle's medium (DMEM; Gibco, 11965-092), 10\% fetal bovine serum (FBS, Thermo, Shanghai, China), 1\% nonessential amino acids (NEAA, Gibco, 11140-050) and 1\% GlutaMAX (Gibco, 35050).

Generation of hiPSCs from adult HDFs. Plat-A packaging cells were plated at $6 \times 10^{6}$ cells per $100 \mathrm{~mm}$ dish and incubated overnight. After 1 day, the cells were transfected with retroviral vector pMXs (encoding Oct4, Sox2, Klf4 and c-Myc) using Lipofectamine 2000 transfection reagent (Gibco, GB11668-019).
At $48 \mathrm{~h}$ after transfection, the medium was collected as the first virus-containing supernatant and replaced with new medium that was collected $24 \mathrm{~h}$ later as the second virus-containing supernatant. The virus-containing supernatants were filtered through a $0.45 \mu \mathrm{m}$ pore-size filter and supplemented with $10 \mu \mathrm{g} / \mathrm{ml}$ polybrene (Sigma, St. Louis, MO, USA, H9268). Equal amounts of virus-containing supernatants containing each of the four retroviruses were mixed before transduction, transferred to the fibroblast dish and incubated overnight. Approximately 50000 fibroblasts per well of a six-well plate were transduced twice over $48 \mathrm{~h}$. Then, the transduced cells were passaged on plates containing irradiated MEFs. The medium was replaced with iPSCs medium, containing DMEM/F12 (Gibco, 11330), 20\% knockout serum replacement (KSR, Gibco, 10828-028), 1\% nonessential amino acids (NEAA, Gibco, 11140-050), 1\% GlutaMAX (Gibco, 35050), $0.1 \mathrm{mM} \beta$-mercaptoethanol (Sigma) and $4 \mathrm{ng} / \mathrm{ml}$ bFGF (R\&D, St. Louis, MO, USA). The first hiPSC colonies appeared $\sim 2$ weeks later and they could be picked after 1-2 additional weeks of culture. Individual colonies were picked and either transferred into a single well of 12-well plates containing IPSC medium and irradiated MEFs. For passaging, hiPSCs were incubated with DMEM/F12 containing collagenase IV $(1 \mathrm{mg} / \mathrm{ml})$ at $37^{\circ} \mathrm{C}$ for $10-15 \mathrm{~min}$. When colonies at the edge of the dish were dissociating from the bottom, the enzyme was removed and washed by iPSC medium without bFGF. Cells were collected by gently pipetting.

RNA isolation and PCR analysis. Total RNA was isolated using the RNAsimple Total RNA Kit (Tiangen, Shanghai, China). Total RNA at $1 \mu \mathrm{g}$ was used for the reverse transcription reaction with the RevertAid First Strand cDNA synthesis kit (Fermentas, Beijing, China). The cDNA from MEFs was used as a negative control, whereas that from hESCs was used as a positive control. RT-PCR was performed using specific sequences: ${ }^{57}$ hOCT3/4-F $5^{\prime}$-GACAGG GGGAGGGGAGGAGCTAGG-3', hOCT3/4-R 5'-CTTCCCTCCAACCAGTTGCCC CAAAC-3'; hSOX2-F 5'-GGGAAATGGGAGGGGTGCAAAAGAGG-3', hSOX2-R 5'-TTGCGTGAGTGTGGATGGGATTGGTG-3'; hKLF4-F 5'-AGAAGCGACAG AATCAAA-3', hKLF4-R 5'-GGACCTGGTATGTGGAGA-3'; hc-MYC-F 5'-GCG TCCTGGGAAGGGAGATCCGGAGC-3', hc-MYC-R 5'-TTGAGGGGCATCGTCG CGGGAGGCTG-3'; hNANOG-F 5'-ACCAGGCACTACCGTAAACA-3', hNANOG-R 5'-CCCTCATCGGGAAGACAG-3'; hLIN28-F 5'-GGATGTCTTTGTGCACCAGA-3', hLIN28-R 5'-CTCCTTTTGATCTGCGCTTC-3'; REX1-F 5'-CAGATCCTAAACAG CTCGCAGAAT-3', REX1-R 5'-GCGTACGCAAATTAAAGTCCAGA-3'; hGAPD H-F 5'-CAAGATCATCAGCAATGCCTCCTG-3', hGAPDH-R 5'-GCCTGCTTCAC CACCTTCTTGA-3'.

Alkaline phosphatase staining and immunocytochemistry. Alkaline phosphatase staining was performed using the Alkaline Phosphatase Detection kit (Si Dan Sai, Shanghai, China, 1102). For immunocytochemistry, cells were fixed with phosphate-buffered saline (PBS) containing 4\% paraformaldehyde (PFA) for $10 \mathrm{~min}$ at room temperature. After washing with PBS, the cells were treated with PBS containing 4\% normal donkey serum (Jackson ImmunoResearch, West Grove, PA, USA, 017-000-121), 1\% bovine serum albumin (BSA, Sigma) and $0.1 \%$ Triton X-100 for $45 \mathrm{~min}$ at room temperature. Primary antibodies included SSEA3 (1:100, Invitrogen, Paisley, UK), SSEA4 (1:100, Invitrogen), TRA-1-60 (1:200, Millipore, Billerica, MA, USA), TRA-1-81 (1:200, Millipore), OCT3/4 (1:100, Santa Cruz Biotechnology, Inc.), SOX2 (1:200, Millipore), TE-7 $(1: 200$, Chemicon, Billerica, MA, USA), rabbit polyclonal antibodies against tubulin $(1: 500$, Cell Signaling, Danvers, MA, USA), mouse monoclonal antibodies against tubulin (1:500, Millipore), rabbit monoclonal antibodies against PTEN (1:100, Cell Signaling), anti-glutamate receptor 1 (AMPA subtype) (1:100, Abcam, Cambridge, UK) and ChAT (1:100, Abcam). Secondary antibodies used were CF488A-conjugated donkey anti-goat IgG $(1: 800$, Biotium, Hayward, CA, USA), CF488A-conjugated donkey anti-rat IgG $(1: 800$, Biotium), CF488Aconjugated donkey anti-mouse IgG $(1: 800$, Biotium), CF488A-conjugated donkey anti-rabbit IgG (1:800, Biotium), Cy3-conjugated donkey anti-rabbit and FITCconjugated donkey anti mouse $\left(1: 300\right.$, Cell Signaling) and incubated at $4^{\circ} \mathrm{C}$ overnight. Cells were then washed three times with $1 \times$ PBS. Mounted MNs were viewed using a Leica (Wetzlar, Germany) TCS SP5 confocal microscope.

Teratoma formation. One million hWT-iPSCs cells were injected subcutaneously into the hind limb muscle of the NOD/SCID mouse (Jackson Laboratory, Bar Harbor, ME, USA). Paraffin sections of formalin-fixed teratoma specimens were prepared 6-8 weeks after injection, and analysis of H\&E-stained tissue sections was performed for each specimen. All animal experiments were performed in accordance with the institutional guidelines. 
Bisulfite sequencing and karyotype analysis. Bisulfite treatment was performed using the EZ DNA Methylation-gold kit (ZYMO Research, Invine, CA, USA), according to the manufacturer's recommendations. PCR primers are: out-forward,

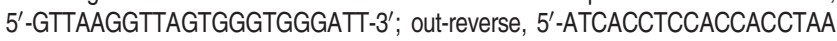
AAA-3'; in-forward, 5'-AGAGAGGGGTTGAGTAGTTTTTT-3'; in-reverse, 5'-ACCT CCACCACCTAAAAAAAAC- $3^{\prime}$. Amplified products were cloned into pMD18-T Vector (Takara, Shiga, Japan). Ten randomly selected clones were sequenced with the M13 forward and M13 reverse primers for each gene. Chromosomal G-band analyses were performed at Tongji Hospital, (Shanghai, China).

Viral vectors. A 19-nt sequence targeting mouse PTEN was subcloned in the pLVTHM genome vector (Addgene plasmid 12247, Cambridge, MA, USA) as previously described. ${ }^{15}$ Briefly, siPTEN sense oligonucleotide $5^{\prime}$-CGCGTCCCCGC CAAATTTAACTGCAGAGTTCAAGAGACTCTGCAGTTAAATTTGGCTTTTTGGA AAT and siPTEN antisense oligonucleotide $5^{\prime}$-CGATTTCCAAAAAGCCAAATT TAACTGCAGAGTCTCTTGAACTCTGCAGTTAAATTTGGCGGGGA were annealed and cloned into the Mlul/Clal-digested vector. Accordingly, scrambled siPTEN sense nucleotide 5 '-CGCGTCCCCCGCAATATTCAATCGAGGATTCAAGAGATCCTCGA TTGAATATTGCGTTTTTGGAAAT and ssiPTEN antisense nucleotide $5^{\prime}$-CGATTTC CAAAAACGCAATATTCAATCGAGGATCTCTTGAATCCTCGATTGAATATTGCGGGG GA were used to generate the control LV-ssiPTEN vector. The third generation of self-inactivating (SIN) lentiviral vector stocks involving four plasmids (pMD.2G, pCMVDR8.92, SIN-W-PGK and pRSV-Rev) were prepared by transient calcium phosphate transfection of the human embryonic kidney 293T cell line as previously described. ${ }^{15,57}$ These vectors were pseudotyped with the vesicular stomatitis virus-G envelope protein. Viral titers were estimated using a FACS assay. ${ }^{15}$ For iPS-derived MNs, PTEN shRNA (h) Lentiviral vector containing three targetspecific constructs that encode 19-25 nt (plus hairpin) shRNA designed to target human PTEN were purchased from Santa Cruz Biotechnology (sc-29459 and control shRNA Lentiviral Particles: sc-108080).

MN culture. Cultures of embryonic spinal MNs were prepared as previously described. ${ }^{15}$ Briefly, the ventrolateral part of the E13 spinal cord was dissected and incubated at $37^{\circ} \mathrm{C}$ for $15 \mathrm{~min}$ in $0.1 \%$ trypsin in Hanks' balanced salt solution. After trituration, cells were plated on dishes precoated with anti-p75 nerve growth factor (NGF) receptor antibody (Abcam, ME20.4, ab8877) in Neurobasal (Gibco) for $30 \mathrm{~min}$. The cells were washed three times with Neurobasal, and the attached cells were isolated from the plate with depolarizing solution $(0.8 \% \mathrm{NaCl}, 35 \mathrm{mM}$ $\mathrm{KCl}$ ) and collected in full media (Neurobasal supplemented with $2 \%$ horse serum, 2\% B27 (Gibco), $0.1 \mathrm{mM} \beta$-mercaptoethanol (Sigma) and $1 \times$ Glutamax (Gibco)). For staining, 2000 cells were plated on poly-DL-ornithine (Sigma) and mouse laminin (Invitrogen)-coated coverslips in four-well dishes (Greiner, Frickenhausen, Germany). For western blots, 100000 cells were plated on each well of 12-well plate also coated with poly-ornithine and mouse laminin. MNs were transduced at $24 \mathrm{~h}$ after plating with multiplicity of infection (MOI) of 10 . For all assays, brainderived neurotropic factor was used at concentrations of $5 \mathrm{ng} / \mathrm{ml}$ and MNs were cultured at $37^{\circ} \mathrm{C}$ with $5 \% \mathrm{CO}_{2}$. Medium was replaced after $24 \mathrm{~h}$ and then every 2 days. AMPA treatment for survival (TUNEL assay) and electrophysiology were carried out from day 7 onwards. Cells were treated with 50, 100, 200, 300, 400, 500 and $600 \mu \mathrm{M}$ (S)-AMPA to determine dose-response effects of AMPA treatments. Of the neurons, $50 \%$ were TUNEL positive at $24 \mathrm{~h}$ following exposure to $300 \mu \mathrm{M}$ AMPA for $1 \mathrm{~h}$. For AMPA inhibition, $50 \mu \mathrm{M}$ CNQX (Sigma) was added to culture medium $1 \mathrm{~h}$ before MNs were exposed to $300 \mu \mathrm{M}$ (S)-AMPA (Sigma) for $1 \mathrm{~h}$ and then fresh medium was applied for $24 \mathrm{~h}$ before performing a TUNEL survival assay. ${ }^{58}$

The iPS-derived MN differentiation. The iPS cells were maintained on gelatinized tissue-culture plastic in iPS media containing DMEM/F12 (Gibco, 11330), 20\% knockout serum replacement (KSR, Gibco, 10828-028), 1\% NEAA (Gibco, 11140-050), 1\% GlutaMAX (Gibco, 35050), $0.1 \mathrm{mM} \beta$-mercaptoethanol (Sigma) and $4 \mathrm{ng} / \mathrm{ml} \mathrm{bFGF} \mathrm{(R \& D)} \mathrm{at} 37^{\circ} \mathrm{C}, 5 \% \mathrm{CO}_{2}$. Medium was changed every $24 \mathrm{~h}$. To generate $\mathrm{MNs}^{23-25} \mathrm{iPS}$ cells were passaged using dispase $(1 \mathrm{mg} / \mathrm{ml})$ and triturated into small cell clumps and placed into ultralow adherent culture dishes (Corning, Corning, NY, USA). For the first 3 days, cells were kept in suspension in iPS medium, to enhance single cell survival, and $20 \mathrm{ng} / \mathrm{ml}$ bFGF (Invitrogen) was added to enhance growth. At day 4, EBs were switched to neural induction medium (DMEM/F12 with L-glutamine; NEAA; penicillin/streptomycin; heparin, $2 \mu \mathrm{g} / \mathrm{ml}$; N2 supplement; Invitrogen). At day 6 , all-trans retinoic acid (RA; $1 \mu \mathrm{M}$; Sigma) was added. The same medium was changed with fresh RA daily.
Hedgehog signaling was initiated on day 15 by application of SHH $(100 \mathrm{ng} / \mathrm{ml}$, R\&D) and purmorphamine (PUR, $1 \mu \mathrm{M}$ ). The same media was changed with freshly daily. At day 28, basal medium was changed to Neurobasal (Invitrogen), containing all previous factors, with the addition of $10 \mathrm{ng} / \mathrm{ml}$ of insulin-like growth factor 1 (IGF-1) and $1 \mu \mathrm{M}$ cAMP (Sigma). At day 35, EBs were dissociated with $0.05 \%$ trypsin (Invitrogen) and plated onto poly-lysine/laminin-coated dishes or coverslips. Plated neurons were cultured in the same medium as above with addition of ascorbic acid (200 ng, Sigma). Cells were transduced with human shRNA PTEN lentiviral vectors with $\mathrm{MOI}$ of 10 for 7 days before assessment. Cells were treated with $50,100,200,300,400,500$ and $600 \mu \mathrm{M}$ (S)-AMPA to determine dose-response effects of AMPA treatment. Approximately $50 \%$ of the cells were TUNEL positive $24 \mathrm{~h}$ after exposure to $300 \mu \mathrm{M}$ AMPA for $1 \mathrm{~h}$. Exposure to AMPA with assays for survival (TUNEL assay) and electrophysiology were carried out from day 45 onwards. For AMPA inhibition, $50 \mu \mathrm{M}$ CNQX (Sigma) was added to culture medium $1 \mathrm{~h}$ before MNs were exposed to $300 \mu \mathrm{M}$ (S)-AMPA (Sigma) for $1 \mathrm{~h}$ and then fresh medium was applied for $24 \mathrm{~h}$ before performing a TUNEL survival assay. ${ }^{58}$

Electrophysiology. Whole-cell electrophysiological experiments were recorded as previously described. ${ }^{14}$ Voltage clamp recordings were performed using an Axon Multi-Clamp 700B amplifier (Axon Instruments, Sunnyvale, CA, USA) using unpolished borosilicate pipettes placed at the cell soma. Pipettes had a resistance of 2-4M $\Omega$ when filled with intracellular solution. Intracellular solution for AMPA- or kainate-induced currents consisted of $120 \mathrm{mM} \mathrm{CsF}, 3 \mathrm{mM} \mathrm{MgCl}$, $5 \mathrm{mM}$ EGTA and $10 \mathrm{mM}$ HEPES (pH adjusted to 7.25 with $12 \mathrm{mM} \mathrm{CsOH}$ ). $\mathrm{Cs}+$ in the pipette solution was included to block $\mathrm{K}^{+}$-dependent membrane conductance. Cells were accepted for study if a stable seal formed with a whole-cell resistance of at least $120 \mathrm{M} \Omega$ and a series resistance of $<10 \mathrm{M} \Omega$. Receptors were activated by focal perfusion of agonists from a micropipette with its tip located $30-50 \mu \mathrm{m}$ from the cell. Three cells were used for dose-response recordings for AMPAinduced whole-cell currents. Currents were recorded in $20 \mathrm{mM}$ extracellular $\mathrm{Na}^{+}$ at $-60 \mathrm{mV}$, in response to AMPA concentrations ranging from $5 \mu \mathrm{M}$ to $5 \mathrm{mM}$. The extracellular perfusion buffer consisted of $15.3 \mathrm{mM} \mathrm{NaCl}, 4.7 \mathrm{mM} \mathrm{NaOH}, 2 \mathrm{mM}$ $\mathrm{CaCl}_{2}, 10 \mathrm{mM}$ HEPES, $10 \mathrm{mM}$ glucose and $228 \mathrm{mM}$ sucrose, $\mathrm{pH}$ 7.40. For the measurement of $\mathrm{Ca}^{2+}$ permeability, $100 \mu \mathrm{M}$ AMPA, close to the $\mathrm{EC}_{50}$ from the dose-response recordings, was used. All extracellular solutions were supplemented with MK- $801(10 \mu \mathrm{M})$, tetrodotoxin $(1.0 \mu \mathrm{M})$ and $\mathrm{Cd}^{2+}(100 \mu \mathrm{M})$ to block NMDA receptors, voltage-gated $\mathrm{Na}^{+}$channels and $\mathrm{Ca}^{2+}$ channels, respectively. Cells were held at a membrane potential of $-60 \mathrm{mV}$. All recordings were performed at room temperature of $21-23^{\circ} \mathrm{C}$. Current recordings were sampled onto an IBM-PC compatible computer using pClamp10 software (Axon). Data were filtered at $3 \mathrm{kHz}$ and sampled at $20-40 \mathrm{kHz}$.

TUNEL staining. Primary cultured or iPS-induced neurons were stained by the TUNEL technique (ApopTag@Red In Situ Apoptosis Detection Kit) according to the manufacturer's instructions (Millipore). MNs were fixed in 4\% PFA in PBS at room temperature for $15 \mathrm{~min}$. MNs were incubated in equilibration buffer for $1 \mathrm{~h}$ at room temperature. The buffer was then removed and samples were incubated in reaction buffer and $\mathrm{TdT}$ enzyme mix at $37^{\circ} \mathrm{C}$ for $90 \mathrm{~min}$. The mix was then replaced with the stop buffer. Samples were kept at $37^{\circ} \mathrm{C}$ for $3 \mathrm{~h}$. They were then washed in PBT and incubated with gentle shaking in blocking solution and antiDIG-rhodamine mix overnight at $4^{\circ} \mathrm{C}$. After that, rabbit anti-tubulin primary antibody (1:500; Cell Signaling) followed by CF488A-conjugated donkey antirabbit IgG $(1: 800$, Biotium) was stained in green as described in the immunocytochemistry methods. Hoechst staining was used to stain nuclei in blue. Mounted MNs were viewed using a Leica TCS SP5 confocal microscope.

Western blot analysis. Primary cultured or iPS-derived MNs were transduced with lentiviral vectors for 7 days and collected from the dishes. Protein extraction for western blotting was performed as described previously. ${ }^{15,16}$ Primary antibodies, anti-mouse glyceraldehyde-3-phosphate dehydrogenase (GAPDH) antibody (1:5000; Calbiochem, Darmstadt, Germany), tubulin (1:5000; Millipore), anti-rabbit PTEN (1:1000; Cell Signaling), AKT (1:1000; Cell Signaling), Bad (1:1000; Cell Signaling), pAKT ser473 (1:1000; Cell Signaling), p-Bad ser155 (1:1000; Cell Signaling), Glutamate receptor 1 (AMPA subtype) (1:1000; Abcam), Glutamate receptor 2 (AMPA subtype) (1:1000; Cell Signaling), Glutamate receptor 3 (AMPA subtype) (1:1000; Cell Signaling), Glutamate receptor 4 (AMPA subtype) (1:1000; Cell Signaling), goat anti-rabbit or mouse HRP secondary antibodies (1:5000; Cell Signaling) were used. 
Statistical analysis. Power analysis was conducted using GPower 3.0 software (Oakland, CA, USA) and statistical analysis was performed using GraphPad Prism v5 (La Jolla, CA, USA). Statistical significance was determined by one-way analysis of variance (ANOVA) depending on the individual experiment as stated in the figure legends.

\section{Conflict of Interest}

The authors declare no conflict of interest.

Acknowledgements. This work was supported by the Ministry of Science and Technology of China (2010CB945200, 2011CB966200) and the Medical Research Council (MRC) UK project grant to KN and PJS (MR/K008943/1). Additional support was provided by the following grants: the National Natural Science Foundation of China (81271369); National Natural Science Foundation of China (81070910); New Century Excellent Talents in University (NCET-10-0606); Shanghai Rising-Star program (11QA1407100); Projects of International Cooperation and Exchanges NSFC (81261130318), the Fundamental Research Funds for the Central Universities and the Shanghai Postdoctoral sustentation Fund, China (Grant No. 12R21416400). PJS is supported by the UK NIHR as a Senior Investigator. JX is supported by National program for support of Top-notch young professionals.

1. Rosen DR, Siddique T, Patterson D, Figlewicz DA, Sapp P, Hentati A et al. Mutations in $\mathrm{Cu} / \mathrm{Zn}$ superoxide dismutase gene are associated with familial amyotrophic lateral sclerosis. Nature 1993; 362: 59-62.

2. Gurney ME, Pu H, Chiu AY, Dal Canto MC, Polchow CY, Alexander DD et al. Motor neuron degeneration in mice that express a human $\mathrm{Cu}, \mathrm{Zn}$ superoxide dismutase mutation. Science 1994; 264: 1772-1775

3. Ferraiuolo L, Heath PR, Holden H, Kasher P, Kirby J, Shaw PJ. Microarray analysis of the cellular pathways involved in the adaptation to and progression of motor neuron injury in the SOD1 G93A mouse model of familial ALS. J Neurosci 2007; 27: 9201-9219.

4. Pehar M, Vargas MR, Cassina P, Barbeito AG, Beckman JS, Barbeito L. Complexity of astrocyte-motor neuron interactions in amyotrophic lateral sclerosis. Neurodegener Dis 2005; 2: 139-146.

5. Boillee S, Yamanaka K, Lobsiger CS, Copeland NG, Jenkins NA, Kassiotis G et al. Onset and progression in inherited ALS determined by motor neurons and microglia. Science 2006; 312: 1389-1392.

6. Yamanaka K, Boillee S, Roberts EA, Garcia ML, McAlonis-Downes M, Mikse OR et al. Mutant SOD1 in cell types other than motor neurons and oligodendrocytes accelerates onset of disease in ALS mice. Proc Natl Acad Sci USA 2008; 105: 7594-7599.

7. DeJesus-Hernandez M, Mackenzie IR, Boeve BF, Boxer AL, Baker M, Rutherford NJ et al. Expanded GGGGCC hexanucleotide repeat in noncoding region of C9ORF72 causes chromosome 9p-linked FTD and ALS. Neuron 2011; 72: 245-256.

8. Renton AE, Majounie E, Waite A, Simon-Sanchez J, Rollinson S, Gibbs JR et al. A hexanucleotide repeat expansion in C9ORF72 is the cause of chromosome 9p21-linked ALS-FTD. Neuron 2011; 72: 257-268.

9. Albo F, Pieri M, Zona C. Modulation of AMPA receptors in spinal motor neurons by the neuroprotective agent riluzole. J Neurosci Res 2004; 78: 200-207.

10. Van Den Bosch L, Van Damme P, Bogaert E, Robberecht W. The role of excitotoxicity in the pathogenesis of amyotrophic lateral sclerosis. Biochim Biophys Acta 2006; 1762 1068-1076.

11. Avossa D, Grandolfo M, Mazzarol F, Zatta M, Ballerini L. Early signs of motoneuron vulnerability in a disease model system: characterization of transverse slice cultures of spinal cord isolated from embryonic ALS mice. Neuroscience 2006; 138: 1179-1194.

12. Kwak S, Kawahara Y. Deficient RNA editing of GluR2 and neuronal death in amyotropic lateral sclerosis. J Mol Med (Berl) 2005; 83: 110-120.

13. Ferraiuolo L, Kirby J, Grierson AJ, Sendtner M, Shaw PJ. Molecular pathways of motor neuron injury in amyotrophic lateral sclerosis. Nat Rev Neurol 2011; 7: 616-630.

14. Brockington A, Ning K, Heath PR, Wood E, Kirby J, Fusi N et al. Unravelling the enigma of selective vulnerability in neurodegeneration: motor neurons resistant to degeneration in ALS show distinct gene expression characteristics and decreased susceptibility to excitotoxicity. Acta Neuropathol 2013; 125: 95-109.

15. Ning K, Drepper C, Valori CF, Ahsan M, Wyles M, Higginbottom A et al. PTEN depletion rescues axonal growth defect and improves survival in SMN-deficient motor neurons. Hum Mol Genet 2010; 19: 3159-3168.

16. Kirby J, Ning K, Ferraiuolo L, Heath PR, Ismail A, Kuo SW et al. Phosphatase and tensin homologue/protein kinase $B$ pathway linked to motor neuron survival in human superoxide dismutase 1-related amyotrophic lateral sclerosis. Brain 2011; 134: 506-517.

17. Liu Y, Wang L, Long ZY, Wu YM, Wan Q, Jiang JX et al. Inhibiting PTEN protects hippocampal neurons against stretch injury by decreasing membrane translocation ofAMPA receptor GluR2 subunit. PLoS One 2013; 8: e65431.

18. Moult PR, Cross A, Santos SD, Carvalho AL, Lindsay Y, Connolly CN et al. Leptin regulates AMPA receptor trafficking via PTEN inhibition. J Neurosci 2010; 30: 4088-4101.
19. Wang H, Wang G, Wang C, Wei Y, Wen Z, Wang $C$ et al. The early stage formation of PI3K-AMPAR GluR2 subunit complex facilitates the long term neuroprotection induced by propofol post-conditioning in rats. PLoS One 2013; 8: e65187.

20. Acebes A, Morales M. At a PI3K crossroads: lessons from flies and rodents. Rev Neurosci 2012; 23: 29-37

21. Chan CB, Chen Y, Liu X, Tang X, Lee CW, Mei L et al. PIKE-mediated PI3-kinase activity is required for AMPA receptor surface expression. EMBO J. 2011; 30: 4274-4486.

22. Takahashi K, Tanabe K, Ohnuki M, Narita M, Ichisaka T, Tomoda K et al. Induction of pluripotent stem cells from adult human fibroblasts by defined factors. Cell 2007; 131: 861-872.

23. Dimos JT, Rodolfa KT, Niakan KK, Weisenthal LM, Mitsumoto H, Chung W et al. Induced pluripotent stem cells generated from patients with ALS can be differentiated into motor neurons. Science 2008; 321: 1218-1221.

24. Amoroso MW, Croft GF, Williams DJ, O'Keeffe S, Carrasco MA, Davis AR et al. Accelerated high-yield generation of limb-innervating motor neurons from human stem cells. J Neurosci 2013; 33: 574-586.

25. Karumbayaram S, Novitch BG, Patterson M, Umbach JA, Richter L, Lindgren A et al. Directed differentiation of human-induced pluripotent stem cells generates active motor neurons. Stem Cells 2009; 27: 806-811.

26. Stambolic V, Suzuki A, de la Pompa JL, Brothers GM, Mirtsos C, Sasaki T et al. Negative regulation of PKB/Akt-dependent cell survival by the tumor suppressor PTEN. Cell 1998; 95: 29-39.

27. Tamura M, Gu J, Danen EH, Takino T, Miyamoto S, Yamada KM. PTEN interactions with focal adhesion kinase and suppression of the extracellular matrix-dependent phosphatidylinositol 3-kinase/Akt cell survival pathway. J Biol Chem 1999; 274: 20693-20703.

28. Lachyankar MB, Sultana N, Schonhoff CM, Mitra P, Poluha W, Lambert S et al. A role for nuclear PTEN in neuronal differentiation. J Neurosci 2000; 20: 1404-1413.

29. Sano T, Lin H, Chen X, Langford LA, Koul D, Bondy ML et al. Differential expression of MMAC/PTEN in glioblastoma multiforme: relationship to localization and prognosis. Cancer Res 1999; 59: 1820-1824.

30. Li L, Liu F, Ross AH. PTEN regulation of neural development and CNS stem cells. J Cell Biochem 2003; 88: 24-28.

31. Li L, Liu F, Salmonsen RA, Turner TK, Litofsky NS, Di Cristofano A et al. PTEN in neural precursor cells: regulation of migration, apoptosis, and proliferation. Mol Cell Neurosci 2002; 20: 21-29

32. Leslie NR, Yang X, Downes CP, Weijer CJ. The regulation of cell migration by PTEN. Biochem Soc Trans 2005; 33: 1507-1508.

33. Backman SA, Stambolic V, Suzuki A, Haight J, Elia A, Pretorius J et al. Deletion of PTEN in mouse brain causes seizures, ataxia and defects in soma size resembling LhermitteDuclos disease. Nat Genet 2001; 29: 396-403.

34. Kwon CH, Zhu X, Zhang J, Knoop LL, Tharp R, Smeyne RJ et al. PTEN regulates neuronal soma size: a mouse model of Lhermitte-Duclos disease. Nat Genet 2001; 29: 404-411.

35. Groszer M, Erickson R, Scripture-Adams DD, Lesche R, Trumpp A, Zack JA et al. Negative regulation of neural stem/progenitor cell proliferation by the PTEN tumor suppressor gene in vivo. Science 2001; 294: 2186-2189.

36. Gary DS, Mattson MP. PTEN regulates Akt kinase activity in hippocampal neurons and increases their sensitivity to glutamate and apoptosis. Neuromolecular Med 2002; 2: 261-269.

37. Omori N, Jin G, Li F, Zhang WR, Wang SJ, Hamakawa Y et al. Enhanced phosphorylation of PTEN in rat brain after transient middle cerebral artery occlusion. Brain Res 2002; 954: 317-322.

38. Ning K, Pei L, Liao M, Liu B, Zhang Y, Jiang W et al. Dual neuroprotective signaling mediated by downregulating two distinct phosphatase activities of PTEN. J Neurosci 2004; 24: 4052-4060.

39. Kwon CH, Luikart BW, Powell CM, Zhou J, Matheny SA, Zhang W et al. PTEN regulates neuronal arborization and social interaction in mice. Neuron 2006; 50: 377-388.

40. Park KK, Liu K, Hu Y, Smith PD, Wang C, Cai B et al. Promoting axon regeneration in the adult CNS by modulation of the PTEN/mTOR pathway. Science 2008; 322: 963-966.

41. Van Den Bosch L, Robberecht W. Different receptors mediate motor neuron death induced by short and long exposures to excitotoxicity. Brain Res Bull 2000; 53: 383-388.

42. Poo MM. Neurotrophins as synaptic modulators. Nat Rev Neurosci 2001: 2: 24-32.

43. Man HY, Wang Q, Lu WY, Ju W, Ahmadian G, Liu L et al. Activation of PI3-kinase is required for AMPA receptor insertion during LTP of mEPSCs in cultured hippocampal neurons. Neuron 2003; 38: 611-624.

44. Zhou Q, Xiao M, Nicoll RA. Contribution of cytoskeleton to the internalization of AMPA receptors. Proc Natl Acad Sci USA 2001; 30: 1261-1266.

45. Van Damme P, Van Den Bosch L, Van Houtte E, Callewaert G, Robberecht W. GluR2-dependent properties of AMPA receptors determine the selective vulnerability of motor neurons to excitotoxicity. J Neurophysiol 2002; 88: 1279-1287.

46. Vandenberghe W, Robberecht W, Brorson JR. AMPA receptor calcium permeability, GluR2 expression, and selective motoneuron vulnerability. J Neurosci 2000; 20: 123-132.

47. Aronica EM, Gorter JA, Grooms S, Kessler JA, Bennett MV, Zukin RS et al. Aurintricarboxylic acid prevents GLUR2 mRNA down-regulation and delayed neurodegeneration in hippocampal CA1 neurons of gerbil after global ischemia. Proc Natl Acad Sci USA 1998; 95: 7115-7120.

48. Tanaka H, Calderone A, Jover T, Grooms SY, Yokota H, Zukin RS et al. Ischemic preconditioning acts upstream of GluR2 down-regulation to afford neuroprotection in the hippocampal CA1. Proc Natl Acad Sci USA 2002; 99: 2362-2367. 
49. Nagai $M, \operatorname{Re} D B$, Nagata $T$, Chalazonitis A, Jessell TM, Wichterle $\mathrm{H}$ et al. Astrocytes expressing ALS-linked mutated SOD1 release factors selectively toxic to motor neurons. Nat Neurosci 2007; 10: 615-622.

50. Hugon J, Vallat JM, Spencer PS, Leboutet MJ, Barthe D. Kainic acid induces early and delayed degenerative neuronal changes in rat spinal cord. Neurosci Lett 1989; 104: 258-262.

51. Carriedo SG, Sensi SL, Yin HZ, Weiss JH. AMPA exposures induce mitochondrial Ca 21 overload and ROS generation in spinal motor neurons in vitro. $J$ Neurosci 2000; 20: 240-250.

52. Koike M, Tsukada S, Tsuzuki K, Kijima H, Ozawa S. Regulation of kinetic properties of GluR2 AMPA receptor channels by alternative splicing. J Neurosci 2000; 20: 2166-2174.

53. Hollmann M, Heinemann S. Cloned glutamate receptors. Annu Rev Neurosci 1994; 17: 31-108.

54. Ning K, Miller L, Burgess LA, Laidlaw HA, Perera N, Downes CP et al. A novel leptin signaling pathway via PTEN inhibition in hypothalamic cell lines and pancreatic $\beta$-cells. EMBO J 2006; 25: 2377-2387.

55. Sarver AL, Li L, Subramanian S. MicroRNA miR-183 functions as an oncogene by targeting the transcription factor EGR1 and promoting tumor cell migration. Cancer Res 2010; 70: 9570-9580.
56. Turecková J, Vojtechová M, Krausová M, Sloncová E, Korínek V. Focal adhesion kinase functions as an akt downstream target in migration of colorectal cancer cells. Transl Oncol 2009; 2: 281-290.

57. Takahashi K, Tanabe K, Ohnuki M, Narita M, Ichisaka T, Tomoda K et al. Induction of pluripotent stem cells from adult human fibroblasts by defined factors. Cell 2007; 131: 861-872.

58. Larm JA, Cheung NS, Beart PM. Apoptosis induced via AMPA-selective glutamate receptors in cultured murine cortical neurons. J Neurochem 1997; 69: 617-622.

59. Raman IM, Zhang S, Trussell LO. Pathway-specific variants of AMPA receptors and their contribution to neuronal signaling. J Neurosci 1994; 14: 4998-5010.

(c) (i) Cell Death and Disease is an open-access journal published by Nature Publishing Group. This work is licensed under a Creative Commons Attribution 3.0 Unported License. To view a copy of this license, visit http://creativecommons.org/ licenses/by/3.0/ 